\title{
Críticas a la filosofía de la liberación desde la postmodernidad y la postcolonialidad
}

Carlos Beorligui

\section{Precisiones iniciales}

Cuando hablamos de la Filosofía de la Liberación (FL), hay que hacer varias precisiones, porque no existe sólo una "filosofía de la liberación", sino varias, con lo cual no es fácil hacer un juicio de valor sobre todas, y presentar las diversas críticas que se han presentado, o se pueden presentar, a cada una de ellas. El primero que realizó una historia y sistematización de las diversas filosofías de la liberación, Horacio Cerutti, indicaba hasta cuatro corrientes diversas dentro de la FL': la ontologista (populismo de la ambigüedad concreta; R. Kusch, M. Casalla), la analéctica (populismo de la ambigüedad abstracta; E. Dussel, J.C. Scannone, O. Ardiles), la historicista (L. Zea, A. A. Roig), y la problematizadora (A. Salazar Bondy, H. Cerutti, Santos). A esas cuatro corrientes habría que añadir la metafísico-realista, de Ignacio Ellacuría y sus seguidores ${ }^{2}$.

Cuando haga referencia en este escrito a la FL, se dará por hecho que estoy hablando especialmente de la segunda corriente, la analéctica, $y$, dentro de ella, de la filosofía de la liberación de E. Dussel. Aunque 
en otros muchos momentos me referiré al conjunto de las filosofías de la liberación, en la medida en que coinciden todas en sus grandes objetivos de fondo: la liberación de las grandes masas de empobrecidos y excluidos del sistema dominante, tanto en Latinoamérica como en el resto de nuestro mundo.

El contenido de esta charla está encaminado a señalar algunas de las características de la FL, su desarrollo interno y vicisitudes por las que ha pasado, pero sobre todo las críticas que hoy día recibe de diferentes corrientes de pensamiento, tanto desde dentro de la propia FL, en su proceso de evolucionar y de acomodarse a los nuevos tiempos, como, sobre todo, desde fuera, por parte de los filósofos que se sitúan en las corrientes denominadas postmodernidad y postcolonialidad.

\section{La FL en el contexto del pensamiento filosófico latinoamericano}

Si lanzamos una breve mirada panorámica al pensamiento filosófico latinoamericano, advertimos que, desde los primeros momentos de la independencia política, los intelectuales más conscientes se interrogan sobre la identidad de Hispanoamérica, y sobre cómo hacer una "filosofía americana" que sea auténtica y original, y a la altura del ser de lo americano. Es la búsqueda de lo que ellos mismos denominan la "independencia cultural", en todos los campos de la cultura, entre ellos el de la filosofía. Así se expresan Alberdi, Sarmiento, A. Bello, Lastarria, Bilbao, etc. ${ }^{3}$. Pero, al lado de este intento encomiable, se advierte en ellos la contradicción de entender la autonomía cultural sólo como un desmarque de la herencia hispana, puesto que consideran que la línea que tienen que seguir es imitar a la Europa más avanzada, Francia e Inglaterra, y, después, a los Estados Unidos.

Esta orientación imitadora cambiará de signo al finalizar el siglo (Martí será un adelantado, en la segunda mitad del s. XIX), y se consolidará en las diferentes generaciones del siglo XX: la de 1900 (Rodó y su "Ariel"), la de 1915 (A. Caso, J. Vasconcelos, J.C. Mariátegui y Haya de la Torre), la de 1930 (Samuel Ramos y Francisco Romero), y la de 1940 (Leopoldo Zea y el grupo Hiperión, A. Salazar Bondy, y otros). Se empieza a rechazar lo que Rodó llama la "nordomanía", o "yankimanía", y a intentar recuperar los valores de la cultura hispana, sin que ello supusiera un volver atrás a la época de la Colonia, y a ningún tipo de dependencia en relación con España. 
Estos intelectuales intentaban situarse entre dos tendencias del momento: el "panamericanismo" norteamericano (teoría imperialista, basada en la doctrina Monroe) y el "iberoamericanismo" (procedente del intento neoimperialista de ciertos intelectuales españoles, acentuado después durante el franquismo). Se trataba de replantearse el viejo problema de la identidad del continente latinoamericano, recurriendo al estudio de la historia de los productos culturales desde la emancipación española, y de las condiciones para llegar a ser autónomo en todos los aspectos. Dentro de este horizonte, la pregunta es cómo hacer una filosofía a la altura de estas circunstancias $\mathrm{y}$ de estos objetivos.

Esta etapa de búsqueda de la identidad cambiará de forma notable hacia 1968, fecha clave en todo el mundo, no sólo en Europa y los EE.UU, sino también en Latinoamérica, porque junto al mayo francés y las revueltas estudiantiles en los EE.UU. (protestas contra la guerra de Vietnam en Berkeley), se da también la Revolución Cultural en China (1966), la matanza de estudiantes en Tlatelolco, "Plaza de la tres culturas" (México, 1968), y el "Cordobazo" argentino (1969) ‘. Es el momento en que surgen las Filosofías de la liberación latinoamericanas, en sus diferentes corrientes, y apoyadas en las diversas matrices culturales que les servirán de incentivo y de apoyo. Esas matrices culturales fueron: la teoría de la dependencia, la teología de la liberación, la pedagogía del oprimido de Paolo Freire, el boom de la literatura latinoamericana y del arte, en general (sobre todo, la muralística mexicana de Orozco, Ribera y Siqueiros), y la propia filosofía de la generación anterior (L. Zea y Salazar Bondy, con sus posturas encontradas).

Las Filosofías de la liberación parten de la conciencia de la dependencia y dominación de Latinoamérica respecto de las naciones más poderosas del primer mundo (centro-periferia), y de la necesidad de la liberación económica y cultural para poder realizarse como personas y como naciones y culturas autónomas. Estos filósofos entienden que si no se dan esas condiciones previas de liberación, no será posible construir una filosofía auténtica y original, sino, como se ha hecho hasta ahora, dominada, mera copia de lo que se hace en el post modernismo.

Cada una de las corrientes se apoyará en diferentes autores o sistemas de pensamiento para fundamentar sus planteamientos. No vamos a detenernos en este punto ${ }^{5}$, porque sería largo y nos desviaría de 
nuestro objetivo, sino referirme sólo al caso de Dussel. El filósofo argentino se apoyará para la construcción de su FL fundamentalmente en el filósofo judío, afincado en Francia, E. Lévinast. La filosofía de Lévinas le sirve a Dussel para dar cuenta de la situación de dominación de Latinoamérica, y para su crítica a la Totalidad ontológica occidental, presentando como alternativa una metafísica de la alteridad, respetuosa de los "otros", de los postergados por el sistema dominante, tanto individuos como culturas.

Así, la cultura occidental, desde la modernidad, no ha respetado a los "otros" (en este caso, América), sino que los ha tratado imponiéndoles no sólo su poderío militar y económico, sino también su cultura, idioma, religión, etc. El "ego cogito" cartesiano había sido precedido por el "ego conquiro" de $\mathrm{H}$. Cortés, dando comienzo entonces a la modernidad europea. En esa relación dialéctica de la modernidad, no se respeta al otro, sino que se le somete e introduce en su lógica de la Totalidad. Frente a ello, la FL propone el método analéctico, respetuoso de la alteridad del dialogante, así como defensor de una nueva totalidad, que se configure bajo la responsabilidad ética de respetar los derechos de todos los individuos y colectivos políticos y culturales.

\section{Los "Estudios subalternos" (Subaltern Studies) y la Filosofía de la Liberación latinoamericana}

\subsection{Los "Estudios subalternos"}

Pero no sólo en Latinoamérica se dieron este tipo de movimientos culturales, sino que por esos años también se producen movimientos similares en otras naciones del llamado mundo periférico, o del Sur.

En la India, en 1970, Ranajit Guha comenzó un análisis de la situación colonial de la India ${ }^{7}$, apoyado al principio en el marxismo clásico, pero después, siguiendo a M. Foucault, "comenzó a salirse de los caminos trillados del pasado innovando en cuanto al estudio de la cultura de las masas populares, grupo o clases subalternas, en la India". Más adelante, se unirán a Guha autores como Gayatri Spivak ${ }^{9}$, Homi Bhabha ${ }^{10}$, Gyan Prakash (Universidad de Princeton), Dipesh Chakrabarty (Universidad de Chicago), Jha Prabhakara (Colegio de México) ${ }^{11}$, y otros. 
Todos ellos coinciden en utilizar en su análisis la metodología de Foucault y Lacan, sin prescindir de Marx, situándose como un movimiento intelectual de "compromiso" político junto a los grupos subalternos. Más adelante se abrieron a problemas de género, de cultura, de política, de crítica del racismo, utilizando nuevos instrumentos teóricos críticos de análisis.

Otra obra que supuso un punto de arranque importantísimo fue la de Edward Said, Orientalism. Western Conceptios of the Orient ${ }^{12}$.

En Africa también aparecieron por esos años obras importantes, como las de Fabien Eboussi Boulaga, La crise de Muntu. Authenticité africaine et philosophie", y Paulin Hountondji, Sur la "Philosophie Africaine". Critique de l'etnopobilosophie ${ }^{14}$.

En conclusión, con esta mirada panorámica resulta curioso observar que se da una coincidencia de fechas entre todos estos Estudios subalternos y la Filosofía de la liberación latinoamericana, nacida también a finales de los años ' 60 , siendo por tanto la primera de estas corrientes críticas contra el centro de la modernidad europea. Todos ellos eran estudios críticos, que partían de su propia vida y situación regional, y utilizaban métodos de análisis similares, en torno al marxismo, estructuralismo, psicoanálisis, etc.

\subsection{Similitudes y diferencias}

Las similitudes entre ambos movimientos parecen evidentes:

- Consciencia de la situación de dependencia, sumisión, dominación, respecto a los parámetros teóricos y culturales del primer mundo;

- Intento de interpretar su situación cultural de una forma nueva, dejando de lado y superando las diversas interpretaciones que les llegan de los teóricos de las Universidades de las Metrópolis;

- Utilización de similares métodos de análisis críticos, especialmente el marxismo acomodado a su situación, el estructuralismo, el psicoanálisis lacaniano, etc.

Pero las diferencias también son significativas en relación con la FL de E. Dussel. 
- En realidad, cada línea de pensamiento dentro de las Filosofía de la liberación, tuvo su horizonte teórico de interpretación, y sólo la cuarta corriente, la problematizadora (de orientación marxista) coincide con los autores anteriores en el método crítico (el resto de las corrientes tienen referencias teóricas diferentes: cultura popular, Lévinas, historicismo, Zubiri).

- Además, Dussel señala que "la Filosofía de la liberación nunca fue simplemente un "pensamiento latinoamericano", ni historiografía de aquel pensamiento. Fue filosofía crítica y localizada autocríticamente en la periferia, en los grupos subalternos"15. Lo que quiere decir Dussel es que se tenía siempre la pretensión de que la FL valía para cualquier cultura periférica.

- Pero la especificidad de la FL de E. Dussel estaba en los autores y corrientes filosóficas en los que se apoyaba.

- La intuición originaria de la FL de Dussel (trad. filosófica, a diferencia de los Estudios Subalternos: antropológico, historicista, o crítica literaria), empujada por los movimientos del 68, comenzó por una crítica de la razón moderna, del sujeto cartesiano, desde la crítica ontológica de Heidegger, lo que le permitió mantener una posición crítica radical de dimensiones ontológico-fundamentales. Además, inspirándose en la Escuela de Frankfurt (sobre todo en Marcuse y El hombre unidimensional), contagió siempre de un sentido político sus análisis ontológicos.

- Influyó también decisivamente la obra de Frantz Fanon, Los condenados de la tierra, ayudando a situarnos en el horizonte de las luchas de liberación de los años ' 60 . De ahí que, como señala Dussel, participaran en las luchas contra las dictaduras argentinas de Onganía, Levingston y Lanusse. Desde la filosofía se trataba de analizar esos hechos y comprometerse en ellos. La consecuencia de todo ello fueron atentados, bombas, asesinatos, y expulsión de la universidad y del país.

- Haciendo un análisis del Sistema-Mundo (Globalización, Teoría de la dependencia, etc.), se llega a la conclusión de que los países del TM han sido víctimas del Yo modemo, "yo conquisto" (H. Cortés, México, 1921), anterior al "yo pienso" cartesiano (Amsterdam, 1637). De ahí la insistencia de Dussel de defender que la modemidad comienza con el descubrimiento de América, 
y no con la filosofía racionalista e ilustrada ${ }^{16}$. Hace, pues, 500 años que se ha ido construyendo el "mito de la modernidad", la superioridad europea sobre el resto de las culturas del orbe. El primer ideólogo “occidental", según Dussel, fue Ginés de Sepúlveda, contrincante de Bartolomé de Las Casas, quien desde 1514 empezó a exponer el primer "contradiscurso" de la Modernidad con sentido global, mundial, centroperiferia".

- Pero el autor más influyente y significativo fue, sin duda, Lévinas. El "Otro" de Lévinas era el "dis-tinto", no el "di-ferente" de J. Derrida ${ }^{18}$, porque la "di-ferencia" se define desde la "identidad"14. Viene a ser el "excluido" y vigilado de los análisis de Foucault sobre las instituciones médicas y carcelarias. Además, el pensamiento de Lévinas se aplica a la situación concreta y política latinoamericana.

- Pero la FL (de Dussel) se separa o supera pronto a Lévinas, especialmente en tres puntos esenciales, como indica el propio Dussel: el otro era concretamente el pobre y toda Latinoamérica; la aceptación de la analogía (frente a Lévinas, cercano a la equivocidad); y la dimensión social del otro ${ }^{20}$. Por tanto, Lévinas se quedaba meramente en la teoría y en la crítica negativa a la Totalidad occidental, no permitiendo sus planteamientos construir una nueva totalidad, una sociedad nueva, en la que se tratara de conseguir la emancipación y la liberación. Por tanto, "localizar" el discurso fue siempre la obsesión de la FL, situándose en la periferia del Sistema-Mundo (Wallerstein), desde las razas dominadas, desde la mujer en el machismo, desde el niño en el sistema de educación bancaria (P. Freire), desde la miseria y pobreza, etc.

Ahora bien, la historia avanza, la sociedad cambia, y los métodos de análisis tienen que irse perfeccionando. $Y$ ante ello, queda planteada la cuestión de si siguen siendo válidos los parámetros de la FL, o han quedado obsoletos, $y$, por tanto, tienen que buscarse paradigmas alternativos para analizar la realidad y para tratar de transformarla.

\section{Los planteamientos críticos respecto a la Filosofía de la Liberación}

La FL, en todas las tendencias, y más todavía en el caso de Dussel, fue evolucionando interiormente, al calor de la reflexión interna y de 
las críticas de otros autores. En el caso de Dussel, tras la época más típica de FL (entre 1969 y 1975), fue evolucionando hacia la crítica del populismo, apoyado en el estudio de la obra de Marx, así como con el diálogo con la Ética del Diálogo de Apel y Habermas, y últimamente en diálogo crítico con los postmodernos y comunitaristas.

Pero algunos pensadores pertenecientes a las Filosofías de la liberación han proclamado que la FL ha muerto, no siendo ya útil y no estando a la altura de las necesidades de Latinoamérica. Por su parte, otros planteamientos teóricos consideran que la FL tiene que ser sustituida por otros paradigmas filosóficos. Vamos a examinar estas propuestas, distinguiendo entre las críticas internas y las externas.

a) Las críticas internas a las que vamos a hacer referencia aquí (dejando de lado la descalificación de $\mathrm{H}$. Cerutti), consideran que la FL sigue siendo válida, pero tiene que corregir algunos planteamientos y ponerse al día. Claro que en estos planteamientos se dan también posturas muy diversas, dependiendo del punto de vista filosófico desde donde se filosofe. En este apartado, vamos a situar las posturas de F. Fornet-Betancourt, J.L. Gómez Martínez, con sus propuestas de FL como diálogo de culturas of filosofía intercultural.

b) Las críticas externas consideran que las Filosofías de la liberación están acabadas, ya no sirven, y tienen que ser sustituidas por otros paradigmas filosóficos. Son las críticas de la postmodernidad y la postcolonialidad. Veamos cada uno de estos dos planteamientos.

\subsection{La superación de la $F L$ desde dentro.}

La aparición de la FL fue un acontecimiento fundamental en el ámbito filosófico de América Latina: se daban con ella las claves profundas de su situación de dependencia y alienación; era un pensar que no se detenía en abstracciones, sino que se orientaba directamente a la acción y la liberación; y poseía suficiente calidad técnica como para situarse a la altura de la filosofía del primer mundo, incluso con pretensiones de situarse por delante, desmontando el carácter opresor y dogmático de su filosofía.

Pero ya desde el principio se vio la complejidad y disparidad de los planteamientos de las diferentes orientaciones o escuelas de la FL, como lo dejaba claro $\mathrm{H}$. Cerutti en su Filosofía de la liberación latinoamericana ${ }^{21}$. El mismo Cerutti fue quien primero, desde dentro de 
la FL expresó la idea de la superación de la FL, ya en 1979². Cerutti siempre fue el más crítico respecto a los planteamientos "populistas" (tanto la línea ontológica como analéctica), por considerarlos poco conscientes de sus posturas y apoyaturas epistemológicas. Pero ahora considera que todas las FLs estarían periclitadas, vacíos y superados sus planteamientos y propuestas por los nuevos acontecimientos mundiales, o insuficientes por sus propias limitaciones internas.

Pero más que seguir a Cerutti en su planteamiento, que, por otro lado, no es muy explícito ni convincente, vamos a seguir la propuesta de Fornet-Betancourt y de J. L. Gómez-Martínez ${ }^{23}$, de una FL como diálogo de culturas.

La propuesta de Fornet-Betancourt, presentada desde la mitad de la década pasada ${ }^{24}$, se sitúa en diálogo crítico con la filosofía de la liberación de E. Dussel, con ánimo de superarla positivamente. Lo que pretende la propuesta de filosofía de diálogo entre culturas es la superación de la postura excesivamente maniquea y agresiva que adopta Dussel, y algunos otros, en la etapa fundacional, en la medida en que se entendía la FL como una ruptura total, tanto con el pasado latinoamericano como con la filosofía europea y norteamericana, y se proponía un inicio desde cero del pensar filosófico latinoamericano.

$\mathrm{Y}$, en segundo lugar, se trata también de explicitar algunos aspectos que ya estaban presentes en la fase inicial de la FL, y orientar la filosofía latinoamericana de la liberación hacia una "filosofía dialógica" (GómezMartínez), o una "filosofía inter-trans-cultural" (Fornet-Betancourt). Veámoslo más en concreto.

a) La FL, sobre todo en la línea de Dussel, nació o se entendió desde una postura de confrontación. Así se entendió la "teoría de la dependencia", por ej., y se montaron desde ahí una serie de categorías de carácter dicotómico: centro-periferia, dominación-liberación, centro nordatlántico-periferia latinoamericana,... Estos planteamientos, aun poseyendo parte de verdad, se va considerando cada vez más como excesivamente cómoda y poco fructífera, porque esos planteamientos no reflejan toda la realidad. Además, se considera que estas posturas de confrontación no hacen más que reproducir el problema, pero al revés, entendiendo ahora que la mejor y única filosofía auténtica es sólo la FL. Así, la filosofía y la cultura oprimidas se convierten, a su vez, en opresoras. 
Con ello, se ha dado la vuelta al planteamiento de E. Lévinas, en su pretensión de superar la cerrazón de la Totalidad occidental desde la dinámica del Infinito, en un diálogo interpersonal e intercultural sin término. De ahí que se piense ahora que esta propuesta de filosofía dialógica e intercultural esté ya presente en las mismas raíces de la propuesta liberadora de Dussel y demás miembros de su corriente filosófica.

b) La nueva línea de pensamiento propuestas por Fornet y GómezMartínez, estaría abriéndose camino a través también de las propuestas de $\mathrm{L}$. Zea, quien indica que no tendría sentido una FL que persiguiera convertirse en dominadora de las otras. Por tanto, esta propuesta trata de presentar el carácter dialógico de la liberación. Surgiría abierta a la modernidad y como una contundente respuesta al discurso postmoderno, sobre todo en lo que tiene de individualista e insolidario, y de negación de la universalidad de la razón y sus implicaciones negativas respecto a las culturas más "débiles".

La FL, en esta corriente dialógica, proyecta la constitución de un diálogo humanista y humanizador, en el que cada individuo y cultura pueda expresar su propio discurso. Frente al estructuralismo (y, en parte, la postmodernidad), que centra el sentido en la sintaxis lógica de las redes de diálogo, esta FL sitúa el sentido en cada hombre como dialogante. Así, todo ser humano, y toda cultura, tienen derecho a crear su propio discurso, y, además, la legitimidad de todo discurso axiológico se encuentra en su relación con el "otro". Aquí se advierte el aporte fundamental de la FL: problematizar el discurso filosófico de la postmodernidad europea, al menos en su dimensión pragmática. Frente a una cómodo postura de "correr la cortina" ante la interpelación del discurso del "otro", le interpela para que acepte ese "otro" discurso, como generación del sentido junto a los demás. De este modo, se problematiza incluso el concepto mismo de "Tercer Mundo", como dialogante de segunda categoría, y se le niega la posibilidad de poner en crisis la propia postura de superioridad e indiferencia.

Así, Leopoldo Zea, en su libro Discurso desde la marginación y la barbarie ${ }^{25}$, señala que es la incomprensión la que considera como "bárbaro" el otro discurso, pues lo considera propio de una sub-humanidad, desde el centro hacia la periferia. Frente a ese modo de pensar, la FL propugna una situación simétrica en los discursos, en la cual todos 
los hombres y culturas son centro, dialogando desde situaciones de igualdad.

Esta propuesta dialógica, surgida hacia los años ochenta, la entienden Fornet-Betancourt y Gómez-Martínez como un intento de problematización, pero también de revalorización, de la FL. Es decir, por un lado, esta propuesta debe problematizar a la propia FL, con sus pretensiones de soberanía, autonomía y autarquía. Lo que importa no es tanto construir una pulcra, sistemática y atractiva filosofía latinoamericana o de la liberación, sino que lo que importa es el "proceso de liberación", en tanto es el sujeto que genera y critica sus propias formulaciones. Por tanto, proceso y teoría son inseparables y mutuamente interactuantes. $Y$, por otro lado, no supone esto declarar que la FL está superada y periclitada, sino revalorizarla, reorientándola hacia esa línea del diálogo simétrico, superando las posturas autosuficientes.

Quien mejor ha profundizado en esta postura y la ha explicitado en diferentes trabajos es Raúl Fornet-Betancourt. Nos vamos a referir especialmente a dos de sus escritos: "Pensamiento iberoamericano como base para un modelo de filosofía intercultural" (1995), e "Introducción: aprender a filosofar desde el contexto del diálogo de las culturas" $(1997)^{26}$.

a) En el primero de ellos, comienza Fornet con una autrocrítica a su postura anterior sobre la FL y su necesidad de inculturar la filosofía en las culturas y circunstancias de Latinoamérica. En escritos anteriores, defendía la necesidad de inculturación y contextualización de la filosofía en las diversas culturas existentes. Eso implicaba que la filosofía posee un núcleo fuerte (un "logos") que se mantiene intacto y sirve para todos los países y culturas. Y ese logos o núcleo se aplica después a cada cultura y contexto filosófico particular. De tal forma que así no se reduce la filosofía a ser repetitiva ni imitadora. Además, la inculturación es la expresión concreta del proceso de historificación del logos.

Pero ahora ve que esta tesis es muy problemática, por no ser suficientemente radical desde la idea que va cobrando la filosofía sobre sí misma. Piensa que los modelos de inculturación (por ej., la postura de J. C. Scannone) ${ }^{27}$ siguen dominados por una concepción del logos filosófico orientado aún demasiado unilateralmente en la tradición occidental fuerte, como si la filosofía tuviera un "núcleo fuerte", que pue- 
de y debe aplicarse a cada cultura. De este modo, el aspecto dinámico e histórico de la filosofía se aplica a la envoltura, pero no a ese núcleo, que representaría la estructura fundamental de la racionalidad filosófica, sancionada por la tradición (occidental). Pero, así, esta idea de filosofía le marcaría a priori las fronteras de sus posibilidades de desarrollo.

En definitiva, lo que haría falta ahora es liberar al logos filosófico de toda estructura racional constituida, para que pueda manifestarse en su originaria potencialidad polifónica. Por tanto, se trata de superar la idea de racionalidad heredada de la tradición occidental, y ensayar la experiencia de lo filosófico como campo de (posibles) sentidos lógicamente abierto e indefinido.

Cada una de estas dos posturas puede ejemplificarse con una metáfora diferente. En la primera postura, la filosofía es un tronco común que va dando flores y frutos distintos, según el injerto o el trasplante propio realizado por la inculturación. Son frutos de cada país, pero salidos de un tronco común a todos los países. En cambio, en la segunda postura, ocurre al revés: se trata de que cada cultura mantenga su tronco, y allí se injerte lo que interese de otros mundos y culturas. Como decía José Martí: "Injértese en nuestras repúblicas el mundo; pero el tronco ha de ser el de nuestras repúblicas"2s.

Para Fornet, esta segunda postura supone un movimiento de transracionalización del logos filosófico, fruto de la aceptación de la solidaria equivalencia de los logos en que hablan las culturas. Y, de este modo, se da la vuelta al problema. Hay que superar la idea de comparar las filosofías desde el punto de vista neutral, trascendente y superior/ ventajoso. La realidad, bien entendida, no da motivos para defender esa postura. Cuando alguien la defiende, está considerando su punto de vista como el absoluto, cuando, en realidad, no pasa de ser uno más entre otros muchos.

Por consiguiente, estamos impelidos no sólo a repensar la comprensión de la filosofía con la que solemos trabajar, sino también a replantear la manera como la tradición occidental tiene de entender la relación con la filosofía. Hay que llegar a una nueva concepción de la filosofía, desdefinirla y liberarla de su definición monocultural, superando la idea que tiene de sí al presentarse como un paradigma universalmente normativo. De ahí que se nos presente ahora como algo 
contingente el desde dónde y el cómo hacer filosofía, y como algo respectivo a otras formas de filosofar. No sería suficiente, por tanto, aceptar que dentro de la filosofía se han dado épocas históricas, superadas por las siguientes, sino que, junto a la tradición filosófica occidental, sancionada como clásica, se dan también perspectivas exteriores, oprimidas, acalladas o minusvaloradas, y que pudieron ser, en su pasado, de otra manera si se les hubiera dejado expresarse con libertad y autonomía.

En conclusión, la contingencia de toda forma de filosofía parecer ser la perspectiva de fondo para intentar responder a la cuestión de cómo hacer filosofía hoy. Se trata, pues, de ver si desde la experiencia cultural de los pueblos de latinoamérica se puede esbozar un plan de filosofía intercultural, o bien, de una filosofía que ser articule desde el diálogo entre culturas. Este intento no significa volver a posturas provincianas o localistas. Pero sí va contra el peligro de ocultar la diferencia cultural bajo el manto opresor de una universalidad decretada monoculturalmente. En cambio, se trata de lograr una universalidad conseguida por la convocación de universalidades históricas, que, mejor que universalidad, habría que denominar pluri-diversidad.

b) En "Introducción: Aprender a filosofar desde el contexto del diálogo de las culturas", Fornet-Betancourt completa sus ideas situando su proyecto de diálogo intercultural en las coordenadas de nuestro mundo. Por tanto, pretende situar la reflexión filosófica en el contexto de la época de la "globalización" en la que nos encontramos. Esta situación supone un reto para el ser humano actual, para la filosofía, y para la propia filosofía de la liberación, dentro de cuya tradición quiere situarse críticamente el autor. Ante esta realidad, la mejor salida que advierte es filosofar desde el diálogo intercultural. De ahí su propuesta de filosofía intercultural.

Pero la filosofía, si quiere ser consecuente con su propia esencia, esto es, dar cuenta de la realidad en toda su profundidad, no puede hacer abstracción del marco histórico-cultural en el que se desarrolla. Este contexto histórico-cultural que nos domina hoy es el de la "globalización", como "proceso resultante de una política económica que se expande mundialmente como la única opción civilizatoria de la humanidad y que, justo por entenderse y quererse imponer como el único proyecto globalizable, no tolera diferencias culturales con pla-

Criticas a la filosofía de la liberación desde la postmodemidad $\checkmark$ in notrontoniolidad 
nes alternativos, esto es, culturas alternativas propias, ni en Occidente ni en ninguna región del mundo"-"y.".

La globalización no sólo no tolera alternativas culturales desde las culturas no occidentales, sino también dentro de Occidente, en la medida que esta estrategia de monopolio cultural pertenece a los grupos dominantes de Occidente que pretenden reducirlo todo a las normas del mercado y del consumo, pretendiendo desde ahí domesticar todas las culturas del mundo.

Nos enfrentamos, por tanto, con una ideología totalitaria, "que roba a las culturas de la humanidad el eje estructural básico para cualquier desarrollo ulterior propio, a saber, el derecho a determinar las formas de dominio sobre su tiempo y espacio"30. Si esto es así, el diálogo intercultural se nos presenta como un horizonte alternativo y un proyecto civilizatorio, que se oponga al "huracán de la globalización", como le llama Hinkelammert ${ }^{31}$.

Así, pues, la tarea de la filosofía se tiene que centrar en este diálogo de culturas. Pero como paso previo, tiene que ser consciente de las condiciones reales con que se está dando hoy este diálogo inter-cultural. Esto es, nos señala Fornet, hay que "aprender a filosofar desde el contexto del diálogo de las culturas"32. Eso supone que hay que comenzar por analizar las condiciones en las que se debe dar ese diálogo, esto es, los elementos económicos, sociales, políticos, etc., que suponen e implican y condicionan ese diálogo.

$\mathrm{Y}$ en ese ejercicio de estudiar las condiciones y contexto de ese diálogo, descubrimos que las culturas no están dialogando en unas condiciones de simetría, sino bajo relaciones de poder. De ahí que la primera tarea de la filosofía intercultural será criticar esas condiciones de asimetría. Para, a continuación, poder establecer un plan de construir un mundo configurado por relaciones inter-culturales basadas en principios que permitan que cada cultura pueda ser ella misma.

En este diálogo intercultural, la filosofía se descubre en medio de un mundo representado por una constelación de visiones culturales de la vida. Todas ellas tienen una especial visión del mundo, y sólo en ese diálogo intercultural podrá llegar la filosofía a ser la base necesaria y auténtica para conseguir la universalización que pretende, pero esta vez de modo auténtico. Es decir, la filosofía tiene que pasar de la fase monológica, afincada en el universo cultural europeo, considerado el 
patrón filosófico-cultural que debía universalizarse, a una nueva universalización, resultado de un diálogo simétrico de todas las culturas. Así, pues, como señala Fornet, "la interculturalidad o, mejor dicho, la práctica de la filosofía desde el contexto y desde las exigencias reales del diálogo de culturas se presenta de este modo como la gran oportunidad para que la filosofía logre una verdadera universalidad" ${ }^{33}$. Sólo desde ese contexto de interculturalidad se podrá acceder a la verdad, el objetivo último de la filosofía.

Ahora bien, en este proceso de búsqueda de un contexto de universalidad, la filosofía queda, por tanto, transformada, reorientada en sus pretensiones de universalidad. Pero, a su vez, "la filosofía en transformación intercultural se convierte en fermento de transformación de las culturas en diálogo ${ }^{\text {34 }}$.

Y esto es lo que produce lo que Fornet denomina un proceso de "desobediencia cultural". Las culturas no son universos simbólicos estáticos y dogmáticos, sino que tienen su propia evolución histórica, fruto de los diálogos entre diferentes líneas o tradiciones dentro de la propia cultura, y en el diálogo con otras culturas limítrofes. Así, vemos dentro de todas las culturas una auténtica lucha entre una pluralidad de tradiciones. $Y$ en esa lucha e intercambio, se producen muchos conflictos, consecuencia de la lucha de cada tradición por hegemonizar esa cultura.

Así, pues, junto a tradiciones que defienden dentro de cada cultura la defensa de los intereses de una minoría privilegiada, que controla el poder en su beneficio, se dan también tradiciones que buscan la liberación y el respeto por los derechos de todos, sobre todo de los más desfavorecidos.

La filosofía intercultural lo que pretende es iluminar este juego de tradiciones dentro de cada cultura, impulsar esa "desobediencia cultural" que impulsa a no tomar como algo cerrado y dogmático la situación cultural fáctica, y tratar de leer la situación de su cultura en clave de diaiéctica de liberación y opresión, y optar por continuar o invertir su cultura desde las memorias de liberación que guarde. En conclusión, para Fornet, "desobediencia cultural es, pues, praxis cultural de liberación" 35 .

Esto implica que la filosofía entienda que liberación e interculturalidad se presentan, dice Fornet, como dos paradigmas complementa- 
rios, lo que supone que "la filosofía (intercultural) cumple su función de transformación de las culturas desde una opción ética universalizable, que es la opción por los oprimidos en todos los universos culturales" ${ }^{36}$.

La conclusión que se desprende de la orientación crítica que posee este tipo de filosofía intercultural, le hace distinguirse claramente de un simple multiculturalismo, en la medida en que éste "quiere lograr una "cultura común" por la yuxtaposición", mientras que la filosofía intercultural que propone $\mathrm{R}$. Fornet, "busca la transformación de las culturas por procesos de interacción, es decir, convertir las fronteras culturales en puentes sin casetas de aduana" ${ }^{37}$.

Como puede verse, la propuesta de Fornet-Betancourt constituye un intento de transformación de la FL desde los nuevos parámetros en los que se sitúa el mundo actual en la época que se está dando por llamar "globalización". Ahora bien, si situamos esta postura en el horizonte de la crítica a la FL de la primera época, hay que reconocer que estos planteamientos los asume plenamente Dussel. Sus extremosidad de la primera época se ha ido atemperando, y ha ido asimilando lo más valioso de la teoría marxiana, y las propuestas de la "etica del discurso" de Apel y Habermas. Y en sus últimos escritos, sitúa siempre sus planteamientos filosóficos desde el horizonte de la globalización, con su actitud dominante y excluyente ${ }^{38}$.

\subsection{La crítica externa a las Filosofías de la Liberación}

Estas críticas van a venir sobre todo de parte de dos nuevos paradigmas filosóficos que están teniendo cada vez más presencia en Latinoamérica: la postmodernidad y la postcolonialidad. La postmodernidad irrumpe en el panorama filosófico latinoamericano durante la década de los ochenta, y la postcolonialidad, durante los noventa. Veamos lo fundamental de ambas corrientes de pensamiento.

\subsubsection{La crítica a la filosofía latinoamericana desde los parámetros de la postmodernidad}

Si la propuesta de Fornet suponía una crítica y un intento de la FL desde dentro, invitándola a situarse en ese contexto de diálogo de culturas, las críticas que vamos a ver a continuación nos sitúan en otro contexto diferente. 
Vamos a presentar los puntos básicos de esta teoría, y realizar después un análisis crítico.

a) La postmodernidad latinoamericana, según S. Castro-Gómez

Uno de los autores que más se proclaman defensores de las claves filosóficas de la postmodernidad y que más se han esforzado por mostrar sus beneficios a la hora de interpretar desde ahí la situación de latinoamérica y defender la pertinencia de una filosofía postmoderna latinoamericana es el filósofo colombiano Santiago Castro-Gómez. Su bibliografía sobre el tema es amplia y digna de ser tenida en cuenta ${ }^{39}$. Yo voy a seguir sus reflexiones sobre este punto en el capítulo primero, "Los desafíos de la postmodernidad a la filosofía latinoamericana", de su excelente libro "Crítica de la razón latinoamericana" $"$.

El concepto de "postmodernidad", como todos los que se convierten en tópicos, tiene una amplia gama de acepciones. Se trata de un movimiento filosófico que surge en Europa, de la mano de autores como Lyotard, Baudrillard, Vattimo, Lipovetsky, y otros, y que resulta también deudor de la corriente que se denominó "postestructuralismo", empalmando con las ideas de Foucault, Derrida, Deleuze, y otros. Pero el mismo autor nos señalará en qué sentido entiende este concepto de postmodernidad, en su aplicación a latinoamérica.

S. Castro-Gómez comienza su análisis haciendo referencia a la afirmación ya citada de $\mathrm{H}$. Cerutti, en el año 1979 , respecto a la necesidad de replantear la filosofía latinoamericana tras la superación de la $\mathrm{FL}^{+1}$. Para Cerutti es evidente que la FL se ha estancado y hay que superarla. Quince años después de estas reflexiones, S. CastroGómez retoma estos planteamientos y se propone mostrar que los enfoques de la filosofía postmoderna son los más adecuados para dar cuenta de la situación de latinoamérica y orientar la filosofía latinoamericana por su verdadero rumbo.

Para eso, comienza haciéndose varias cuestiones: "¿Qué tipo de transformaciones socio-culturales han apresurado el envejecimiento de las categorías filosóficas, sociológicas y teológicas de los discursos liberacionistas?". "¿Cuáles aportes nos es posible retomar de estos discursos para un diagnóstico contemporáneo de las sociedades latinoamericanas?". Y "¿qué clase de reajuste categorial tenemos que realizar para consolidar un nuevo tipo de discurso crítico en América Latina? ${ }^{n 42}$. 
Para Castro-Gómez, la situación de latinoamérica y del mundo entero durante la década de los ochenta ha cambiado totalmente respecto a las décadas anteriores, por lo que están estas circunstancias invalidando los análisis que fueron típicos de la FL: la teoría de la dependencia: culpabilidad única de los males de latinoamérica al posmodernismo; la $\mathrm{fe}$ en las reservas morales y revolucionarias del pueblo; y la utopía de una sociedad en la que no existan ya antagonismos de clase.

Todos estos tópicos piensa Castro Gómez que ya no se sostienen. Durante los '80, los movimientos de liberación fueron aplastados, el socialismo europeo cayó, y se ha incrementado la pobreza y la distancia entre pobres y ricos. De tal modo que ha sido denominada a esta década la "década perdida".

Castro Gómez se detiene en presentar las críticas que muchos autores latinoamericanos, de la línea de la FL, han hecho a la postmodernidad, tratándola de ideología al servicio de los intereses del capital en este época de neoliberalismo/neoconservadurismo.

Pero su empeño consiste en hacernos ver que esas críticas están equivocadas y están haciendo ver las propias limitaciones de la FL para tener un diagnóstico acertado sobre lo que están pasando en latinoamérica y en el resto del mundo.

Castro Gómez considera que la postmodernidad no es un fenómeno puramente ideológico, sino un cambio de sensibilidad a nivel del mundo de la vida, y que se da no sólo en el primer mundo sino también en la periferia. Por tanto, no es una trampa en que habrían caído algunos intelectuales del Tercer Mundo, como quieren hacer creer algunos filósofos de la liberación, sino que es un estado generalizado de la cultura, presente también en América Latina.

Para probar esta afirmación, hecha mano de varios sociólogos latinoamericanos, como Martín-Barbero, D. García-Delgado, Roberto Follari, N. Lechner, B. Sarlo, etc., todos ellos coincidentes en mostrar los efectos en latinoamérica de una nueva sensibilidad social, caracterizada por los siguientes rasgos:

1) Escepticismo ante los ideales heroicos que predicaba la anterior generación, ante el fracaso de los intentos liberacionistas;

2) Tránsito de una "cultura holista" a otra de corte "neoindividualista", centrada no en identidades amplias (nación, continente) sino restringidas (grupos pequeños, familia, amigos,...); 
3) La identidad nacional se disuelve en identidades supranacionales, debido a la cultura que transmiten los medios de comunicación;

4) Cultura escéptica frente a los grandes relatos, desplazándose hacia “ideologías livianas" ("pensamiento débil”, G. Vattimo);

5) Abandono de la militancia política, orientada a las luchas por la liberación, para orientarse a prácticas más individuales y de búsqueda directa de la propia satisfacción personal: música, ecología, familia, religión (micro-prácticas).

R. Follari, argentino, señalaría como causa de todo esto: la brutalidad de las dictaduras militares frente a los grupos revolucionarios; y la falta actual de alternativas sociales. Todo esto desembocaría en una "cultura de la inmediatez", en donde lo importante es aprender a sobrevivir hoy, que mañana ya veremos lo que ocurre. $\mathrm{El}$ presente se convierte en el horizonte único de significación, por falta de un proyecto futuro.

Esto es lo que hace surgir una "sensibilidad pesimista" que no viene de fuera, sino que surge de dentro. Todas las promesas que el pensamiento de la liberación había hecho, han resultado fracasadas; y este fracaso formaría ya parte de la "memoria colectiva" del pueblo latinoamericano, por lo que cualquier oferta política de hacer realidad el orden prometido le resulta indiferente y sospechoso.

De ahí que estaríamos en un momento (dice N. Lechner, chileno) en que la política se está desprendiendo de todo elemento redencionista, y despojándose de cualquier motivación ético-religiosa. El resultado de todo ello es el desencanto político y la inflación ideológica. Además, la política aparece ante la gente como un espectáculo montado por los mass media, en donde el carisma del líder es algo producido por criterios estético-publicitarios (ej.: la campaña entre Fujimori y Vargas Llosa, en Perú).

Por tanto, advertimos la enorme y progresiva influencia de los medios de comunicación en la formación de la conciencia de las masas y de sus imaginarios simbólicos y culturales. Con lo cual, se produce, según ellos, la relativización de la propia cultura, sustituida por otra más universal y trans-nacional.

Según el sociólogo chileno, J.J. Bruner, los mass media habrían realizado en AL una biperrealidad simbólica, en donde los significantes ya

Críicas a la filosofio de la liberación desceo la postmodemidad $v$ lo mostcoslonintided 
no remitirían a significados, sino a significantes desterritorializados. Esto implica que la socialización del individuo se remite en gran parte a criterios y pautas transnacionales de comportamiento, distanciándose de su propia cultura. Esta cultura de masas lo que hace es disolver las certezas tradicionales (que eran antes garantía de integración social), formándose ahora una escena compleja en donde conviven lo nacional y lo transnacional.

Si al efecto de los mass media se une la socialización intensiva y masiva que se está haciendo a través de la escuela, que transmite una concepción moderna del mundo, de corte occidental, científico, hace que la distinción entre cultura alta y cultura popular se va diluyendo en latinoamérica. La cultura popular no puede competir con la escolarización, la industria cultural, y los medios de comunicación. Incluso, cuando la cultura popular se utiliza, se convierte en "folclor", modificado como producto de consumo dentro de los canales de consumo de ocio.

El autor, Castro Gómez, se apresura a decir que "diagnosticar un "desencanto" político y cultural en América Latina no significa estimular el abandono de la lucha política en aras de asumir formas de vida nihilista, como pretenden los detractores de la postmodernidad"43. Es que, dice Castro Gómez, el desencanto de la gente no viene del rechazo del desarrollo científico-técnico, ni el hartazgo del consumo, sino ante el fracaso de todos los proyectos de transformación social afiliados a una concepción "iluminista" (ilustrada) del mundo.

No se trata, por tanto, de un desencanto "ontológico", sino que se origina ante el rechazo de una cierta forma de entender la política y el ejercicio del poder. Y esa es la razón de que empiecen a surgir los llamados Nuevos Movimientos Sociales (NMS), que expresan su total desconfianza en la política formal. Son redes horizontales que pretenden sustituir las verticales, políticas, pidiendo una descentralización del poder político.

Las conclusiones que Castro Gómez saca son dos: en primer lugar, la postmodernidad es un "estado de ánimo" profundamente arraigado entre nosotros, si bien por causas diferentes con las que se produce este fenómeno en el postmodernismo; $y$, en segundo lugar, la postmodernidad no viene de la mano con el neoliberalismo, pues una cosa es el desencanto que se da en el nivel del "mundo de la vida", y 
otra muy distinta es la tendencia homogeneizadora de una racionalidad sistémica y tecnocrática, como la que representa el neoliberalismo.

En una última parte, Castro Gómez se detiene en defender de las críticas de los FLs y tratar de explicar en su hondo sentido los más importantes tópicos de la postmodernidad y del postestructuralismo, como son "el fin de la modernidad", el "fin de la historia", la "muerte del sujeto", y el "final de las utopías".

Todos sus análisis están llenos de ambigüedades y juegos de palabras, que se esfuerzan siempre por defenderse de los ataques de falta de opción por la justicia social y de defensa de los intereses de los más explotados y excluidos de la tierra. Se defiende Castro Gómez señalando que las luchas en nombre de la "igualdad" y de la "justicia social" suelen degenerar casi siempre en su contrario.

Además, apoyado en la teoría sobre el "poder" de Foucault (no hay poderes buenos o malos; el poder es el juego de fuerzas que atraviesa a dominadores y a dominados), considera que el combate por la injusticia no hace más que generar nuevas formas de injusticia. Entonces la pregunta es: icuáles injusticias son más o menos tolerables para el conjunto de la sociedad? Pero esto es una cuestión que no puede ser decidida a priori desde ningún metalenguaje universal, sino que deberá ser decidido en un debate público, donde cada parte haga valer su argumento, y en donde el disenso pueda ser pacíficamente regulado.

Esto supone soñar o proponer la utopía de un mundo futuro. Pero no todas las utopías se reducen a apoyarse en los relatos unitarios de la modernidad. Existen otro tipo de formas narrativas, que siguen aportando una función utópica, pero con ingredientes distintos a los valores de la modernidad (unidad, consenso, armonía, homogeneidad, ausencia de injusticia y reconciliación).

Frente a esas utopías, propone el siguiente modelo: la utopía de un mundo policéntrico, desde el punto de vista económico-político, y pluralista desde el punto de vista cultural. Esto significa, por tanto, no el fin de las utopías, sino de las utopías de tipo moderno, ilustrado. Se trata de construir una nueva sociedad, pero sobre nuevos parámetros. Pero, sigue diciendo Castro Gómez, "después de Auschwitz, Hiroschima y Ayacucho (Gustavo Gutiérrez: "lugar de los muertos"), sólo podemos entender ese cambio bajo el paradigma de la diversidad

Criticas a la filosofia de la lberoción desde la postmodemidad $\checkmark$ la bostcoloniatidad 
y la heterogeneidad, a riesgo de repetir la tentación a convertir la razón en irracionalidad" +4 .

Estas palabras conclusivas parecen querer decir que para el filósofo postmoderno, a diferencia del pensador crítico y del filósofo de la liberación (que extrae las raíces del pensar desde el sufrimiento de las "víctimas"), lo importante no es la experiencia del sufrimiento y el empuje para superarlo, sino la posibilidad de ejercer el disenso y la diferencia.

\section{b) Análisis crítico sobre la postmodernidad.}

Pienso que en relación con los planteamientos de Castro Gómez hay que enfocarlos diferenciando tres aspectos: su diagnóstico sobre latinoamérica, la explicación genética sobre esa realidad, y las propuestas de cambio y transformación que propone para los países latinoamericanos.

1) Empezando por el primer punto, creo que no se puede negar a los postmodernos el acierto en bastantes de los puntos que indican en sus análisis de la situación cultural latinoamericana. Los sociólogos en los que se apoyan son de primer nivel, serios y rigurosos, y ni siquiera todos ellos defienden las tesis del paradigma postmodernos, sino que van mostrando en sus análisis sociológicos que en las dos últimas décadas está cambiando muchas cosas en la sociedad latinoamericana, entre otras cosas por efecto de la influencia del fenómeno de la globalización.

Basta que repasemos las más significativas de sus afirmaciones, y echemos una mirada a la sociedad latinoamericana, para darnos cuenta de que sus descripciones son bastante acertadas. Aunque también hay que ser conscientes de que la sociedad es siempre más compleja de lo que las generalizaciones de los sociólogos nos quieren indicar. Nos indican estos estudiosos que se da actualmente en la sociedad latinoamericana.

- Un escepticismo ante los ideales heroicos,

- Un tránsito de una cultura holista a otra de corte neoindividualista,

- Una tendencia a la identidad nacional frente a otras de tipo transnacional (aunque este rasgo es ambiguo, y complementado con la tendencia a la globalización, en el que insisten los teóricos de la postcolonialidad), 
- Una cultura escéptica frente a los grandes relatos: pensamiento débil,

- El abandono de la militancia política,

- La tendencia al goce del presente ante las promesas de futuro,

- Una orientación al esteticismo y un nuevo misticismo, etc.

La pregunta que habría que hacerse es a qué segmentos de población se puede decir que alcanzan estos rasgos: ¿es una minoría selecta, en lo económico y cultural, muy accidentalizada, o abarca también amplios sectores de las mayorías populares, como pocos recursos, pero muy influenciadas también por los mass media?

2) Pero, junto a estos aciertos descriptivos, tenemos que señalar los graves errores en la explicación de esta situación socio-cultural.

Las afirmaciones de Castro Gómez, y algunos sociólogos en los que se apoya, parecen apuntar como causa de estos cambios de sensibilidad más al fracaso de los llamados movimientos liberacionistas que a intervenciones de factores militares, políticos, culturales y económicos de las potencias del primer mundo. Parecería que estos fenómenos novedosos surgen de modo neutral, como por generación espontánea, y fruto de una evolución cultural que, iniciada en la postmodernidad, les ha llegado a los latinoamericanos, porque les tocaba, como a un árbol, al cabo de un cierto tiempo, le toca madurar y dar los frutos correspondientes.

Castro Gómez insiste en que estos síntomas postmodernos no son flores importadas, debido a intereses neoliberales. Faltaría más. Se trata de "un estado de ánimo" profundamente arraigado entre nosotros, los latinoamericanos. Y ese estado de ánimo, como señala Follari, habría sido generado, entre otros factores, por la represión que las dictaduras militares ejercieron sobre los movimientos de liberación. Si con esto se quiere decir que, junto con factores externos, también han intervenido fuerzas represivas internas, estariamos de acuerdo. Pero eso no cambia el análisis. Lo importante es cuestionarse si esta nueva sensibilidad y estado de ánimo es algo neutro y espontáneo, o resultado de una planificada operación de imponer una cultura uniforme, la neoliberal, a través de todos los medios posibles de que dispone: medios económicos, políticos, militares, $y$, en no menor medida, los medios de comunicación. 
De fondo, parece que la estrategia explicativa de los postmodernos estaría apoyándose en una cierta epistemología basada en un darwinismo social. Es decir, habría de fondo una cierta inclinación a pensar y a hacer creer que las posturas liberacionistas no pueden ser verdaderas porque no han tenido éxito en la historia reciente latinoamericana. Como si se pudiera hacer un paralelismo entre verdad y éxito histórico. La gente de la calle ya no creería en ellas porque no les han solucionado los problemas que tenían. Y está desilusionada. $\mathrm{Y}$ ahora vuelve la vista a las promesas de la sociedad capitalista, que no resuelve todos los problemas, pero llena los estómagos.

En ese sentido, una teoría filosófica que no es capaz de ver estos intereses de fondo, no puede por menos que ser considerada como una ideología al servicio de esos intereses neoliberales, de quienes pretende no depender, pero a quienes sirve $\tan$ bien con su ceguera $e$ inconsciencia. Y, por eso, tienen razón los filósofos de la liberación cuando consideran a estas teorías postmodernas de ideologías al servicio del neoliberalismo imperante en la actualidad ${ }^{+5}$. Estas evidencias se muestran más claramente aún al analizar sus propuestas de salida para la situación actual latinoamericana.

3) Este punto es seguramente el punto más débil de la postmodernidad. Ya hemos oído a Castro Gómez señalar que el oponerse a las utopías liberacionistas, a su filosofía de la historia y demás propuestas de cambio social, así como constatar un desencanto político en latinoamérica, no significa promover la pasividad y el abandono de la lucha política. La postmodernidad no propone el nihilismo, ni una pasividad cínica ante las insuficiencias de la sociedad. El problema está en que el análisis de la realidad social y las propuestas utópicas desde los relatos unitarios de la modernidad (en los que se seguiría apoyando, según Castro Gómez, la FL) ya no son válidos ni convincentes.

Para este análisis social se apoya en Foucault y en su teoría de los equilibrios de poder como configuradotes últimos de la sociedad. Dada la imposibilidad de una racionalidad unitaria, no habría modo de establecer criterios definitivos para calificar a un poder como bueno y correcto, y a otro como malo. Además, la experiencia histórica habría mostrado que el combate por la justicia suele desembocar y generar nuevas formas de injusticia. Esto no nos cierra a proponer utopías de futuro, pero no las del estilo de la modernidad, sino otras configura- 
das por el equilibrio de centros de poder, caracterizados por un policentrismo en lo económico-político, y un plaralismo en lo cultural.

Este modo de pensar parece indicar que para los filósofos postmodernos lo importante no es tanto trabajar por un mundo justo, desde la experiencia del sufrimiento de las víctimas, como es el caso de la FL, sino más bien asegurar un mundo donde sea posible ejercer el disenso, la diferencia. Parecería, pues, que no se han parado a pensar si cabe pensar en un mundo en el que se puedan conjugar a la vez la justicia y la diferencia, lo universal y lo particular. Dan por hecho que la exigencia de justicia sólo se podría alcanzar desde el dogmatismo y la imposición de regímenes estalinistas. Es cierto que cabe ese peligro, $\mathrm{y}$, de hecho, se ha dado en ciertas ocasiones, pero el reto está precisamente en no renunciar a la lucha por la justicia (cosa que sólo puede hacerse desde criterios universalistas), manteniendo también el derecho a ejercer el disenso, la diferencia, pero un disenso no desde la satisfacción y la insolidaridad, sino desde la defensa de los derechos de las minorías marginadas.

En ese sentido, la gran objeción que hay que hacer a los postmodernos es su renuncia a una nueva universalidad de la razón ética, que supere las limitaciones de la razón moderna occidental, para alcanzar una nueva universalidad racional y ética, conseguida desde un consenso universal de todos los afectados, individuos y culturas.

No se trataría, en este caso, de una universalidad desde arriba, impositiva y dogmática, sino de una universalidad desde abajo, desde el diálogo abierto de todas las culturas e individuos, sin excluir a nadie de ese diálogo.

\subsubsection{El nuevo paradigma de la "postcolonialidad"to}

En los años noventa se inicia en Latinoamérica la influencia de una corriente de pensamiento que continúa y profundiza los llamados Subaltern Studies, que, referidos en un primer momento a la situación de post-colonialidad de las naciones pertenecientes a la influencia británica, se contagia después a otros ámbitos culturales, y en concreto también a la situación latinoamericana.

a) El contexto de su nacimiento.

Para Dussel, "los Subalternal Studies" procedentes de la India, el "pensamiento" y la "filosofía africana" afroamericana y afrocaribeña, 
en pleno desarrollo, permitieron discutir la innovadora hipótesis de una "razón postcolonial (post-colonial reason)", que surgió en Asia y Africa después de la emancipación de naciones de dichos continentes a partir de la II Guerra europea del siglo XX"+7.

Estos autores asiáticos y africanos, llegados a las Universidades norteamericanas, empezaron a publicar el resultado de sus experiencias y el modo como veian la relación entre el centro en el que ellos se ballaban y sus paises periféricos de origen. Es, por tanto, una nueva teoría interpretativa de las relaciones entre el centro y la periferia, que surge en la década de los '90, que surge de la mano de profesores universitarios, provenientes de varias ex-colonias inglesas y emigrados a universidades de los USA, y tambien europeas.

Reflejan de modo muy expreso y directo la situación en la que estos intelectuales se encuentran. Los tres que se consideran originadores de esta forma de pensar, y que acuñan el término "postcolonial", son Edward Said, Homi Bhabba y Gayatri Spivak (los tres mayores teóricos del postcolonialismo), sobre cuyas obras ya hemos hecho referencia más arriba.

La situación en la que se encontraban ellos suponía un cúmulo de ambigüedades: están en países y universidades del llamado primer mundo, ricas y dotadas de todos los medios necesarios, pero son conscientes de que no son uno más de ese mundo; $y$, por otro lado, se encuentran entre sus compatriotas inmigrantes, venidos de sus mismos países para conseguir un puesto de trabajo, pero tampoco son como ellos, por su nivel económico y cultural. Por tanto, se ven desde una doble posición hegemónica: frente a sus localidades de origen, por su condición de profesionales que han tenido éxito; y frente a los otros inmigrantes, que están en el mismo país de acogida que él, la mayoría de los cuales luchan por sobrevivir y salir adelante.

Esta situación tan ambigua les lleva a revisar el papel que las narrativas anticolonialistas y tercermundistas habían asignado al intelectual crítico, y a buscar nuevas formas de concebir la relación entre teoría y praxis. Se consideran a sí mismo unos entes "híbridos", que no tienen otro punto de vista desde el que ejercer sus análisis más que desde esa "hibridez" y zona fronteriza. 
Los contenidos fundamentales de esta teoría serían los siguientes:

- La situación en la que se encuentran los países del llamado Tercer Mundo, y el mundo en general, obliga a cambiar de paradigma, de esquema teórico, con el que interpretar la realidad de esos países considerados periféricos, explotados, colonizados, para adoptar otros modos de pensar y de actuar.

- Esos cambios se refieren a lo que ellos llaman el paradigma del "colonialismo", ante el que ellos se ven más allá (post-). El colonialismo fue la teoría central que predominó en los años sesenta y setenta, estimulada por los procesos de "liberación nacional" (sobre todo, los vividos en Asia y África, dentro del Imperio inglés). Esa teoría giraba en torno a dos ejes principales: El Estado metropolitano, por un lado, y el estado nacional-popular, por otro. Este estado nacional-popular era considerado como el agente de liberación y de descolonización en el Tercer Mundo.

- Ellos consideran que esta forma de pensar ya no sirve para la actualidad. En el momento actual, estaríamos en un mundo globalizado, atravesado por redes globales (a las que ya hemos hecho referencia al hablar de la postmodernidad), que los unen tanto a la metrópoli como a la periferia. Así como a exclusiones de tipo económico, racial y sexual, que operan más allá y más acá de la nación.

Esta teoría, como hemos dicho ya, se inicia en medio de intelectuales que provenían de las antiguas colonias inglesas, y están impregnados sus planteamientos de las circunstancias en que se dio esta colonización y descolonización dentro del entorno del imperio inglés, como bien lo señala Bart Moor-Gilbert, en su libro Postcolonial Theory ${ }^{+8}$.

En la interpretación que realizan sobre sus países de origen, estos intelectuales se adhieren a "la crítica radical de la metafísica occidental que se articula en la línea de Nietzsche, Weber, Heidegger, Freud, Foucault, Lacan, Vattimo, Deleuze y Derrida. Al igual que estos autores europeos, los teóricos poscoloniales señalan la complicidad fundamental de Occidente $-\mathrm{y}$ de todas sus expresiones institucionales, tecnológicas, morales o científicas - con la voluntad irrestricta de poder sobre otros hombres y otras culturas" ${ }^{49}$. Pero no se limitan a repetir a estos críticos europeos, sino que profundizan su crítica desde un nivel más hondo, en dos sentidos, como indican Santiago Castro-Gómez y Eduardo Mendieta.

Criticos a la filosofio de la liberoción descle la postmodernidad v len nnetronennintirtar 
El primero de estos aspectos de crítica y profundización se refiere a que "ninguno de los autores arriba mencionados tematizó los vínculos entre la metafísica occidental y el proyecto europeo de colonización. Por el contrario, todos ellos permanecieron recluidos en el ámbito de una crítica intraeuropea y eurocéntrica, que fue incapaz de levantar la mirada por encima de sus propias fronteras" $"$. A este respecto, Spivak criticó en sus escritos a Foucault y Deleuze por su eurocentrismo y por ignorar la división internacional del trabajo ${ }^{51}$. Consideran los teóricos postcoloniales que las primeras víctimas de la modernidad y del capitalismo occidental no fueron los trabajadores europeos y del primer mundo, sino los indígenas nativos de las colonias de los imperios occidentales. Precisamente fue posible la industrialización europea por la acumulación de recursos naturales y de riqueza que provenía de las diferentes colonias. Así, es evidente que sin el colonialismo depredador no hubiera sido posible la ilustración y la modernidad occidental.

El segundo aspecto en el que profundizan su crítica se orienta a considerar que los ámbitos desde los que estos teóricos europeos pretenden superar la metafísica occidental: el arte (Nietzsche), la contemplación mística (Heidegger), la "religión débil" (Vattimo), los deseos (Deleuze), etc., están todavía impregnados por sueños, fantasías y proyectos coloniales. En contraposición, "los teóricos poscoloniales reconocen que todas las categorías emancipatorias, aun las que ellos mismos utilizan, se encuentran ya "manchadas" de metafísica"

Por tanto, no se trata de pretender situarse en un ámbito exterior a lo occidental, una región específica "posoccidental", configurada por los diferentes segmentos sociales marginados (el Tercer Mundo, las mujeres, los pobres, los obreros, etc.), sino que de lo que se trata, según Spivak es de "jugar limpio; de poner las cartas sobre la mesa y descubrir qué es lo que quiere lograr políticamente con una determinada interpretación" ${ }^{53}$. Spivak es consciente de que todo intérprete lo hace desde una situación concreta, $y$, por tanto, lo fundamental según él no está es el horizonte teórico en el que se sitúan los conceptos a los que apela una filosofía colonialista crítica (libertad, diferencia, sujeto, alienación, etc.), sino la función performativa que posean.

Un dato importante respecto a estos teóricos postcoloniales es que sus teorías surgieron en los departamentos de literatura, de crítica literaria, de estas universidades, y no tanto en departamentos de filo- 
sofía. "Esto es debido, nos explica Dussel, entre otras razones, a que una cierta izquierda marxista norteamericana fue expulsada de los departamentos de filosofía y se hicieron presentes en los departamentos de crítica literaria, literatura comparada o lenguas romances (en especial el francés), lo que dio a estos estudios un vuelo teórico nunca antes alcanzado (ni en Estados Unidos, ni tampoco en Europa. La preponderancia en el uso de filósofos franceses (Sartre, Foucault, Derrida, Lyotard, Baudrillard, etc.) se explica igualmente porque es desde los departamentos en lengua francesa (y no la inglesa más tradicional y bajo control de un pensamiento más conservador) que dicho movimiento inicia sus trabajos" ${ }^{54}$.

La tesis de Dussel es que cuando en los departamentos de literatura inglesa empezaron a participar intelectuales provenientes de Asia, África y del Caribe, es cuando el panorama irá cambiando, adoptándose planteamientos más críticos, similares a los de la $\mathrm{FL}^{55}$. Y actualmente se está propagando este planteamiento también en amplios círculos de intelectuales latinoamericanos, situados también en Universidades norteamericanas, y, más recientemente en europeas (alemanas, sobre todo $^{\text {56 }}$. Desde esas tribunas académicas, han introducido cambios de interés en los marcos teóricos interpretativos de los estudios latinoamericanos, especialmente en la crítica literaria ${ }^{57}$, relevando a la línea de estudio del "pensamiento latinoamericano", en manos de filósofos. Estos intelectuales latinoamericanos van a plantear, durante la década de los 90, un nuevo enfoque a los "estudios latinoamericanos" $\$$.

\section{b) La postcolonialidad aplicada a Latinoamérica.}

Estos intelectuales advierten los puntos interesantes que este paradigma de la "postcolonialidad" posee para aplicarlo a Latino América, pero reaccionan indignados e irritados ante las afirmaciones de algunos de estos teóricos de la "postcolonialidad", como Spivak, cuando afirma que Latino América no habría participado hasta el presente en el proceso de descolonización, o también frente a la exclusión sistemática de la experiencia colonial iberoamericana por parte de Said, Bhabba y otros teóricos postcoloniales ${ }^{59}$.

Esto produce irritación e indignación, porque supone no reconocer que Latino América se descolonizó siglo y medio antes que las colonias inglesas, y todo su pensamiento ha girado precisamente en la 
dirección de buscar su identidad tras el proceso emancipatorio realizado a comienzos del s. XIX.

De ahí que los intelectuales latinoamericanos hayan reaccionado de forma muy diversa. Mientras unos consideran que esta teoría refleja la situación especial de las ex-colonias inglesas, y no es aplicable al ámbito latinoamericano, otros consideran que puede aplicarse a LA, con las correspondientes salvedades. A su vez, otros consideran que estos planteamientos representan un cúmulo de limitaciones que se aprestan a señalar en sus diferentes trabajos críticos.

Pero hay también quienes consideran que estos planteamientos se aplican perfectamente al caso latinoamericano ${ }^{6 c}$. Consideran valiosa de esta teoría la llamada de atención a los profundos cambios que está experimentando el mundo entero, como resultado de procesos enteramente globales, que afectan a todos los países del mundo, y que están obligando a lo que llaman ellos "una translocalización discursiva a ellos vinculada”.

Esa translocalización discursiva se daría entre dos paradigmas: las narrativas anticolonialistas, $y$ las narrativas post-coloniales.

a) Las narrativas colonialistas siempre estuvieron presentes en el pensamiento latinoamericano, desde incluso los tiempos de la Colonia, como en Bartolomé de Las Casas, y sobre todo desde la emancipación, en pensadores como Francisco Bilbao (Chile), J. B. Alberdi (Argentina), José Martí (Cuba), J. E. Rodó (Uruguay), y otros muchos. Estas narrativas fueron acticuladas en espacios tradicionales de acción, esto es, en situaciones donde los sujetos formaban su identidad en contextos predominantemente locales, y no sometidos todavía a procesos intensivos de racionalización (Weber-Habermas), provenientes de la cultura dominante globalizadora.

Según esto, la crítica al colonialismo (de parte de estas narrativas anticoloniales) pasaba por el rescate de la autenticidad cultural de los pueblos colonizados. Así, el concepto de "autenticidad" jugaba en esa narrativa un papel de arma ideológica en la lucha contra los invasores, a quienes se consideraba destructores del "legado cultural" y la "memoria colectiva" de los colonizados.

Y los guardianes de esa autenticidad, los encargados de representar e interpretar el sentir y los intereses del pueblo eran los intelectuales, 
que ejercían la función de "arieles" (referencia al libro de J. E. Rodó), eran los "intelectuales críticos" que podían impugnar al colonizador en su mismo idioma, utilizando los mismos instrumentos racionales y los mismos conceptos.

Como puede verse, estos elementos describen perfectamente el hilo vertebrador del pensamiento latinoamericano de los dos siglos que hemos descrito antes, $y$, por tanto, en esta matriz anticolonialista es donde se formó lo que estos teóricos denominan el "locusenuntiationis" del latinoamericanismo.

b) Frente a esas premisas, las narrativas postcoloniales se articulan dentro de contextos postradicionales de acción, esto es, en localidades donde los sujetos sociales configuran su identidad interactuando en procesos de racionalización global, y donde las fronteras culturales empiezan a volverse borrosas. De ahí que estos intelectuales ya no se ven como "arieles", "profetas" que tengan que hablar en nombre del oprimido, porque no están en su misma situación; ni tampoco como "guardianes" de ninguna "tradición cultural" extraoccidental, o como representantes intelectuales del Tercer Mundo.

En este modo de pensar hay un elemento fundamental que define a estas teorías postcoloniales. Su crítica al colonialismo, dicen ellos, no viene motivada por la creencia en un ámbito moral o cultural de "exterioridad" frente a Occidente, ni tampoco por la idea de un retorno nostálgico a formas tradicionales o precapitalistas de existencia. Ellos dan por hecho que la occidentalización es un fenómeno planetario sin retorno, y que el único camino viable para todo el mundo es aprender a negociar con ella. Así define Spivak su postura frente a la globalización: "una crítica permanente frente a aquello que no se puede dejar de desear".

Las críticas que a estos planteamientos han realizado los teólogos de la liberación van desde considerar este paradigma como configurado por parámetros que no sirven para LA, sino exclusivamente para los ámbitos culturales de las excolonias inglesas ${ }^{61}$, hasta entender que este modo de pensar refleja la situación de unos intelectuales que están en un terreno de "hibridez", pero no vale para los pueblos de origen que están en otra situación. Estos intelectuales olvidan todo el trabajo de intelectuales latinoamericanos, que, desde hace siglo y medio, vienen reflexionando sobre la independencia cultural de Latinoamé- 
rica, y especialmente desde los años sesenta, con la teoría de la dependencia y la filosotía de la liberación ${ }^{62}$. Por otro lado, se les acusa de plegarse demasiado a la situación de globalización, como lo refleja claramente la frase de Spivak citada más arriba, así como de tener un modelo de globalización que representa el del capitalismo neoliberal (imposición de un monismo cultural: mercado y consumo capitalista) ${ }^{6.3}$, $y$, por otro lado, no haber en este modo de pensar ningún aliento liberador, sino un cierto fatalismo ante el avance arrollador del "huracán" globalizador que se lleva todo lo que se pone por delante, como señala Hinkelarnmert.

\section{Conclusiones finales}

Tras este recorrido que hemos realizado a los elementos básicos de las FLs, su evolución interna, así como las críticas realizadas contra ellas por los postmodernos y postcoloniales, llegamos a las siguientes conclusiones:

1) Todas las corrientes analizadas, tanto las internas a la FL como sus contrincantes, parten del hecho de que nos hallamos en un mundo diferente al de tres o cuatro décadas atrás. Un mundo sometido al fenómeno de la "globalización" o "mundialización". En ese sentido, la FL, y Dussel en concreto, no es ajeno a esta realidad, y ha acomodado su pensamiento a esta nueva perspectiva. De hecho, Dussel tiene una excelentes aportaciones críticas al fenómeno de la modernidad $^{64}, \mathrm{y}$ toda su Etica de la liberación en la época de la globalización y de la exclusión ${ }^{65}$ está enfocada precisamente desde estos planteamientos.

2) Lo que diferencia, por tanto, a estas corrientes es el modo como describen y explican esta época de la globalización, así como las soluciones que ante ella proponen. En este punto, la filosofía intercultural de Fornet-Betancourt y la FL de Dussel no tendrían grandes diferencias. Dussel propone, y realiza, el diálogo intercultural entre Norte-Sur y entre Sur-Sur ${ }^{\text {th }}$, estableciendo para este diálogo el criterio formal de la ética del discurso, propuesta por Apel y Habermas.

3) En relación con la postmodernidad, la primera constatación que hay que hacer, como el mismo Dussel se encarga de recordarlo, es que el concepto de "postmoderno" y "postmodernidad" lo utilizó 
él antes que Lyotard ( $L a$ condición postmoderna), puesto que su planteamiento filosófico, apoyado en las críticas de Lévinas a la filosofía heideggeriana y europea, lo consideró un pensamiento postmoderno, superador de la modernidad europea, eurocéntrica y dominadora de los países periféricos, a quienes considera "bárbaros", "irracionales", "lo otro que la razón"6?. Pero Dussel considera como filosofía alternativa un pensamiento que acoja en igualdad los planteamientos de los otros (culturas, sexos, clases sociales, generaciones futuras, etc.), constituyendo una filosofía "transmoderna", más amplia que la postmodernidad europea ${ }^{68}$.

4) Pero las diferencias respecto a la postmodernidad y la postcolonialidad sí que son significativas, y dignas de señalarse y de tenerse en cuenta. Dussel entiende que la FL tiene que aprender de e integrar muchos aspectos positivos de sus planteamientos, y, de hecho, así lo hace. Pero señala varios aspectos en los que la FL tiene una ventaja respecto a esos paradigmas oponentes ${ }^{69}$ :

a) La FL se sitúa sus planteamientos en el ámbito filosófico, mientras que los otros se sitúan más bien en el área de la crítica literaria.

b) La postmodernidad y la postcolonialidad, al basar sus planteamientos metodológicos en filósofos europeos, tienen el peligro de localismo, necesitándose un planteamiento más globalizador. Por ello es por lo que Dussel considera que estos planteamientos "deben ser "reconstruidos" desde un horizonte mundial (ya que, por lo general, piensan eurocéntricamente), y a partir de muchas exigencias hoy ineludibles, tales como la comprensión del diálogo (si lo hubiere) intercultural en la estructura del sistema que se globaliza. Globalización-exclusión (nueva aporía que no debe simplificarse fetichistamente) enmarca la problemática de las otras dimensiones"

5) Pero hay otras objeciones más serias, como la oposición al antifundamentalismo de los postmodernos desde la recuperación de una razón universal ${ }^{\prime 1}$. No se trata de volver a las pretensiones de la modernidad e ilustración europea de convertirse en la intérprete de la racionalidad universal, sino de superarla desde otros parámetros universalizadores. "No se trata, dice Dussel, de una mera defensa de la razón por la razón misma. Se trata de la defensa de las vícti-

\section{3}

Críicos a la filosofío de la liberación desde la postmodernidad

vin nneinninnimalisant 
mas de los sistemas presentes, de la defensa de la vida humana en riesgo de suicidio colectivo. La crítica de la "razón moderna" no le permite a la Filosofía de la Liberación confundida con la crítica de la razón como tal, con respecto a sus tipos o ejercicios de racionalidad. Muy por el contrario, la crítica de la razón moderna se hace en nombre de una racionalidad diferencial (la razón ejercida por los movimientos feministas, ecologistas, culturales, étnicos, de la clase obrera, de las naciones periféricas, etc.) y universal (como la razón práctico-material, discursiva, estratégica, instrumental, crítica, etc.)" ${ }^{m / 2}$.

Lo que Dussel tiene bien claro es que desde la mera y única insistencia en el derecho a discrepar y a ser diferente, frente al dogmatismo uniformizador de la razón moderna, no se favorece a las víctimas, a los explotados y dominados por cualquier poder injusto, sino que sirve precisamente para lo contrario, para dejar libre el camino a los explotadores al no haber criterios universales para echarles en cara su inmoralidad. La solución está en saber conjugar una razón universal basada en la defensa de toda vida humana, y legitimada y concretada a través del consenso de todos los afectados, con el correspondiente respeto a las diferencias y al disenso. De ahí que concluya Dussel: "La cuestión no es Diferencia o Universalidad, sino Universalidad en la Diferencia, y Diferencia en la Universalidad"'?

Piensa Dussel que no es suficiente para apoyar las pretensiones anti-fundamentalistas apelar a la incertidumbre y falibilidad humanas, porque se puede aceptar tales limitaciones, y, por ello, considerar que no caben en el ámbito de la praxis ético-política más que acciones limitadas, acciones e instituciones "con pretensiones de bondad", y, al mismo tiempo, "describir las condiciones universales o los principios éticos de dicha acción ética o política. Universalidad $e$ incertidumbre permiten, exactamente, descubrir la inevitabilidad de las víctimas, y desde ellas se origina el pensamiento crítico y liberador propiamente dicho"'7.

6) Además, la FL atiende realmente al problema de las diferencias, aspecto tan central de la postmodernidad europea. Pero las diferencias a las que la FL hace referencia son las reivindicaciones de los movimientos feministas, ecologistas, los que luchan contra la discriminación racial, a favor de los inmigrantes, y contra todo tipo de 
marginación económica, los campesinos, los pueblos de Tercer Mundo, las naciones periféricas empobrecidas, ..., que son, para Dussel las "víctimas" de la Modernidad, de la Colonización y del Capitalismo transnacional y tardío ${ }^{75}$. Estos grupos de "diferentes" no aspiran a seguir siendo sin más "diferentes", y a que se les permita seguir así, sino que aspiran a un nuevo orden mundial, basado en orientaciones universales de justicia y de verdad, configurado no desde instancias verticales de poder, sino desde la concurrencia y la participación simétrica de todos los afectados, individuos y colectivos de todo tipo (aplicación del "principio formal crítico" de la Etica de la liberación ${ }^{76}$ de Dussel).

7) De este modo se advierte que, mientras la metodología crítica que los postmodernos europeos utilizan se basa en aspectos que priman la estética y lo lúdico, la FL se centra sobre todo en desarrollar una ética basada en la económica, que privilegia el principio material y la defensa de toda vida humana, desde la constatación de las víctimas del "Sistema-Mundo" que domina la realidad. Este olvido de la realidad económica de nuestro mundo, tras el desprestigio del marxismo y de los países que lo habían adoptado como régimen político, es una de las principales limitaciones que Dussel advierte en las teorías postmodernas $"$.

8) Respecto a la postcolonialidad, Dussel reconoce sus aciertos, de los que la FL tiene que aprender, pero recoge las limitaciones que se les suelen hacer a este paradigma: hay que adaptar esos planteamientos a LA, que lleva adelanto respecto a ellos en sus críticas a la situación de dependencia, sus planteamientos reflejan más la "hibridez" de los intelectuales que la situación de los pueblos de los que proceden, se pliegan demasiado a la situación actual de la globalización, y, por tanto, carecer en muchos casos de aliento liberador.

9) Por todo ello, piensa Dussel que la FL tiene suficientes recursos teóricos para afrontar los desafíos que la situación latinoamericana tiene que afrontar, dentro de este mundo cada vez más globalizado. Considera que la FL ha sido criticada desde diferentes puntos de vista, parcialmente desde dentro y desde posturas como la de $\mathrm{H}$. Cerutti, K.-O. Apel y E. Schutte, y en su globalidad desde la exterioridad de la postmodernidad y la postcolonialidad. 
Frente a quienes consideran que la FL está agotada, Dussel piensa que "sólo ahora al comienzo de este siglo se va descubriendo, abriendo nuevos horizontes de profundidad que permiten un diálogo Sur-Sur, preparatorio de futuros y creativos diálogos Sur-Norte, es decir, de Africa, Asia, América Latina y Europa oriental, incluyendo las minorías del "centro""78.

Así, pues, piensa Dussel que la FL sigue siendo vigente y adecuada para afrontar la nueva realidad del mundo en que vivimos, y que categorías como "exterioridad", "alteridad", "totalidad", y otras, siguen siendo adecuadas para esta tarea de análisis y de liberación que necesitan las grandes mayorías empobrecidas y marginadas, cada vez más, en nuestro mundo. En definitiva, la FL, movimiento postmoderno avant la lettre, propiamente transmoderno, "aprecia la crítica postmoderna pero la descentra desde la periferia mundial y la reconstruye desde las exigencias concretas de los grupos subalternos"79.

\section{Notas}

1. Cfr. Cerutti, H., La filosofia de la liberación latinoamericana, México, FCE, 1992 $\left(2^{\circ}\right.$ ed.).

2. Esta última no la tiene en cuenta Cerutti en sus análisis. Cfr. Beorlegui, C., "La influencia de Lévinas en la filosofía de la liberación de E. Dussel y J. C. Scannone", Realidad (UCA, San Salvador), $1997,1^{\circ}$ parte: $n^{\circ} 57$, pp. $243-274 ; 2^{\circ}$ parte, $n^{\circ} 58$, pp. 347-371.

3. Cfr. Zea, L., El pensamiento latinoamericano, México, 1965; $3^{\circ}$ ed.: Barcelona, Ariel, 1976.

4. Cfr. para estos datos, Dussel, E., “La filosofía de la liberación. Los Subaltcrn Studies y el pensamiento postcolonial norteamericano", en Id., Hacia una filosofic política crítica, Bilbao, Desclée de Brouwer, 2001, pp. 435-452.

5. Cfr. Cerutti, H., o.c.

6. Cfr. Levinas, E., Totalidad e infinito, Salamanca, Sígueme, año; Id., De otro modo que ser, o más alla que la esencia, Salamanca, Sígueme, año; Dussel, E. y' Ardiles, O., Liberación latinoamericana y Emmanuel Léimas, Buenos Aires, Ed. Bonum, 1975; Beorlegui, C., "La presencia de Lévinas en la filosotía de la liberación de E. Dussel y J.C. Scannone", o.c. .

7. Cfr. "On some aspects of the Historiography of colonial India", en R. Guha-G. Spivak, Selected Subaltemal Studies, Oxford University Press, New York, 1988. Este estudio, como hace ver E. Dussel, escapa a los estudios tradicionales de "historiografía de la India" del mundo anglosajón, para iniciar un enfoque nuevo, basado en Marx, Foucoult y Lacan. En ello se daría un parecido con la FL.

8. Dussel, E., "La filosotia de la liberación, los Subaltern Studies y el pensamiento postcolonial norteamericano", o.c., p. ++1 . 
9. Cfr. "Subaltern Studies: Deconstructing Historiography and Value", en SPIVAK, G., In Other Worlds. Essays in Cultural Politics, Merhuen, New York. 1987: Id.. Outside in the Teaching Machine, Routledge, New York-London, 1993; Id., "Can the Subaltern Speak?", en William. P./Chrisman, L., Cononial Discurse and Postcolonial Theory, Columbia University Press, New York, 1994, pp. 66-111.

10. Cfr. The Locution of Culture, Routledge, New York-London, 1994. De esta obra ha escrito E. Said: "His work is a landmark in the exchange between ages, genres and the cultures; the colonial, post-colonial, modernist and postmodern", se sitúa en una fecunda "localización (location)": el "se-entre", el "in-between (ness)" supera las dicotomías sin negarlas unilateralmente. Trabaja en la tensión y en el intersticio. Bahbha no nicga el centro ni la periferia, el género ni la clase, la identidad ni la diferencia, la totalidad ni la alteridad (se refiere frecuentemente a la "otherness of the Other" pensando explícitamente en Lévinas), sino que explora la fecundidad del "ser-entre" del "border land" de la tierra, del tiempo, de las culturas, de las vidas, como un "lugar" privilegiado de localización creadora. Se ha superado la dualidad y no se ha caído en su pura negación. La Filosofía de la Liberación, sin negar sus intuiciones originarias puede aprender mucho, crecer. Bhabha asume una negación simplista del marxismo, como muchos postmodernos latinoamericanos, que sin advertirlo caen en posiciones conservadoras, $\mathrm{y}$ hasta reaccionarias.

11. Con estos tres autores dice Dussel que coincidió en el Seminario de la Universidad de Duke, Coss-genealogies and Subaltern Knowledges (15-18 de octubre, 1998), convocados por Walter Mignolo. Cfr. DUSSEL, E., o.c. p. 441.

12. Londres, Penguin Books, 1978.

13. París, Présence Africaine, 1977.

14. París, Maspero, 1977.

15. Dussel, E., o.c., p. 442 .

16. Cfr. Dussel, E., 1492. El encubrimiento del Otro. Hacia el origen del mito de la Modemidad, Madrid, Nueva Utopía, 1992; Id., Hacia una filosofia política crítica, Bilbao, Desclée de Brouwer, 2001, últimos capítulos.

17. Cfr. Ibídem, o.c., p. 444. Cfr. también, dentro del mismo libro, el cap. XVIII, "Sistema-Mundo y Transmodernidad"; Id., 1492. El encubrimiento del Otro. Hacia el origen del mito de la Modernidad.

18. Cfr. Derrida, J., "Violence et métaphysique", Revue de Métuphysique et de Morale (París), 69/3 (1964), pp. 322-354.

19. Cfr. Dussel, E., Para una ética de la liberación latinoamericana, tomo I, Siglo XXI, Buenos Aires, 1973; Id., Filosofia de la Liberación, México, Edicol, 1977.

20. Cfr. Beorlegui, C., o.c., $2^{\circ}$ parte.

21. ()..

22. Cfr. Ceratti, H., "Posibilidades y límites de una filosofía latinoamericana después de la "filosofía de la liberación", en La Filosofít en América. Trabajos presentados en el $I X$ Congreso Ineramericano de Filosofia", Caracas, Sociedad Venezolana de Filosofia, 1979, tomo 1, pp. 189-192.

23. "El pensamiento de la liberación: hacia una posición dialógica", en Heredia Soriano, A. (ed.), VIII Seminario de Historia de la Filosofia Española e Iberoamericana, Salamanca, Universidad de Salamanca, 1995, 359-366. 
24. Cfr. R. Fomet-Betuncourt (ed.), Kulturen der Philosophie. Documentation des I. Internationalen Kongresses für Interkulturelle Philosophie. Aachen, 1996, Pp. 713.; Id., 'Pensamiento iberoamericano como base para un modelo de filosofía intercultural", en Heredia Soriano, A., (ed.), VIII Seminario de Historia de la Filosofía Española e Iberoamericana, Salamanca, Universidad de Salamanca, 1995, pp. 367-375; Id., "Introducción: aprender a filosofar desde el contexto del diálogo de las culturas", Revista de Filosofía (Univ. Iberoamericana), XXX (1997), ${ }^{\circ}$ 90, 365-382; Id., Filosofia intercultural, México, Universidad Pontificia, 1994; Id., Hacia una filosofía intercultural latinoamericana, San José (Costa Rica), DEI, 1994; Id., Estudios de filosofia latinoamericana, México, UNAM, 1992.

25. Barcelona, Anthropos, 1988.

26. Ambos trabajos han sido citados en nota 24.

27. Cfr. Beorlegui, C., o.c., $1^{\circ}$ parte, sobre J. C. Scannone.

28. "Nuestra América", Obras Completas, La Habana, 1975, tomo 6, p. 18.

29. Id., "Introducción: Aprender a filosofar...", o.c., p. 367.

30. Ibídem, p. 368.

31. Franz Hinkelammert, "El buracán de la globalización: la exclusión y la destrucción del medio ambiente vistos desde la teoria de la dependencia", Pasos, 69 (1997), 21-27.

32. O.c., 369.

33. Ibídem., p. 375 .

34. Ibídem, p. 376.

35. Ibidem, p. 380.

36. Ibídem, p. 380.

37. Ibidem, p. 381.

38. Cfr., entre otros escritos, Dussel. E., Ética de la liberación en la edad de la globalización y de la exclusión, Madrid, Trota, 1998; Id., Hacia una filosofía politica crítica, Bilbao, Desclée, 2001.

39. "Los desafíos de la postmodernidad a la filosofía latinoamericana", Disenso (Tübingen), 1995, $\mathrm{n}^{\circ}$ 1, 270-286; Crítica de la razón latinoamericana, Barcelona, Puvill Libros, 1996; Castro-Gómez, S. y Mendieta, Ed. (eds.), Teorias sin disciplina. Latinoamericanismo, post-colonialidad y globalización en debate, México, Grupo Porrúa/Univ. of S. Francisco, 1998.

40. S. Castro-Gómez, "Crítica de la razón latinoamericana", Barcelona, Puvill Libros, S.A., 1996.

41. Se refiere a la ponencia de Cerutti en Caracas, en 1979, dentro del IX Congreso Interamericano de Filosofía: "Posibilidades y límites de una filosofía latinoamericana después de la "Filosofía de la Liberación", en La Filosofía en América. Trabajos presentados en el IX Congreso Interamericano de Filosofia, Caracas, Soc. Venezolana de Filosofía, 1979, tomo I, pp. 189-192.

42. O.c., p. 16.

43. O.c., p. 29.

44. O.c., p. 45

45. Cfr. los filósofos de la liberación cuyas críticas hacia la postmodernidad recoge Castro Gómez en su artículo, pp. 117-22.

46. Cfr. Moore-Gilbert, Bart, Postcolonial Theory. Contexts, Practices, Politics, Londres, Verso, 1997; GUGU wa Thiong'o, Decolonising the Mind : The Politics of Language in African Literature, Portsmouth, Heinemann, 1986. 
47. Dussel, E., o.c., p. +47 .

48. O.c.

49. Castro-Gómez, S./Mendieta, E. , (eds.), Teorias sin disciplima. Latinoamericanismo, postcolonialidad y globalización èn delsate. México, Porrúa/Univ. of S. Francisco. 1998, p. 17.

50. Ibídem, p. 17-18.

51. Cfr. Spivak Gayatri, "Can the Subaltern Speak?", en Williams, P./Chrisman, L. (ed.), Colonial Discourse and Postcolonial Theory, Nueva York, Columbia University Press, 1994. Tambièn hacen críticas similares a Foucault, a pesar de la fuerte influencia que en ellos tuvo, Said (ctr. Culture and Imperialism, Nueva York, Alfred Knopf, 1993, p. 81) y Bhabha (The Location of Culture, Londre, Routledge, 1994, p. 236 y ss.).

52. Castro-Gómez., S./Mendieta, E. (eds.), o.c., p. 19. Las comillas son de los autores.

53. Ibídem, p. 19

54. O.c., p. 447.

55. O.c., p. 447, nota al pie de página $n^{\circ} 33$.

56. Es el caso de S. Castro-Gómez y Altonso de Toro, cuyos textos citaremos más adelante.

57. La Asociación de Estudios Latinoamericanos (LASA) se fundó en 1963.

58. Cfr. Seed, Patricia, "Colonial and Postocolonial Discurse", en Lutin Americam Research Review, 1991, n 3.

59. Cfr. Castro-Gómez, S./Mendieta, Ed. (eds.), Teorías sin disciplina. Latinoamericanismo, post-colonialidad y globalización a debate, México, Porrúa/ Univ. of S. Francisco, 1998, p. 20. En la nota 4, hacen referencia a esta exclusión de los autores latinos en los libros de los teóricos sajones.

60. Toro, Alfonso de (ed.), Postmodemidad y postcolonialidad. Breves reflexiones sobre Latinoamérica, Madrid, Frankfurt, Iberoamericana/Vervuert, 1997; Toro, A. de/Toro, F. de (eds.), El debate de la postcolonialidad en Latinoumérica, Madrid, Frankfurt, Iberoamericana/Vervuert, 1991; Castro-Gómez, S./Mendieta, E. (ed.s), Teorias sin disciplina, o.c.; Castro-Gómez, S., "Narrativas contramodernas y teorías poscoloniales. La propuesta hermenéutica de Walter Mignolo", Praxis (Costa Rica), 1997, n 50, pp. 379-402.

61. Cfr. Klor de Alva, Jorge, "Colonialism and Postcolonialism as (Latin) American Mirages", en Colonial Latin Ameriona Reziew', 1992, n 1-2; Adorno, Rolena, "Reconsidering Colonial Discourse for Sixteenth -and Seventeenth- Century Spanish America", en Latin American Research Review', 1993, n 3.

62. Cfr. Vidal, Hernán, "The Concept of Colonial and Postcolonial Discourse. A Perspective from Literary Criticism", en Latin Americal Research Review, 1993, $n^{\circ} 3$.

63. Para un estudio completo, y desde diferentes puntos de vista, del paradigma de la postcolonialidad, ctr. los diferentes trabajos contenidos en la selección de Castro-Gómez, S., y Mendieta E. (eds.), o.c.

64. Cfr. los últimos capítulos de Hacia una filosofía política critica, o.c., y 1492. El encubrimiento del Otro. Hacia el origen del mito de la Modernidad, o.c.

65. Madrid, Trotta, 1998.

66. Cfr. Hacia una filosofía política critica, o.c., cap. XVII, p.384-385. 
67. Cfr. Dussel, E., Método para una filosofia de la liberación latinoamericana, Salamanca, Sígueme, 1976.

68. Dussel habla en varios de sus escritos últimos de "transmodernidad", en vez de "postmodernidad": cfr. Para una filosofía política crítica, o.c., los últimos capítulos; y el trabajo de confrontación con Vattimo, ya citado.

69. Cfr. Ibídem, p. 449 y ss.

70. Ibídem, p. 449.

71. Cfr. Dussel, E., Postmodernidad y transmodemidad. Diálogos con la filosofía de Gianni Vattimo, México, Universidad Iberoamericana, 1999.

72. Dussel, E., o.c., p. 450.

73. Ibídem, p. 450.

74. Ibídem, p. 450.

75. Ibídem, p. 451.

76. Madrid, Trotta, 1998.

77. Cfr. Dussel, E., Postmodernidad y Transmodernidad. Dialogos con la filosofía de Gianni Vattimo, o.c.

78. Ibídem, p. 451.

79. Ibídem, p. 452. 